\title{
Antikörperbestimmungen gegen Rötelnantigen. Externe Qualitätssicherung: Ergebnisse der INSTAND-Ringversuche 1979-1985
}

\author{
U. P. Merten, Köln \\ Institut für Standardisierung und Dokumentation im medizinischen Laboratorium e.V., Düsseldorf
}

\section{Einleitung}

Eine Rötelnepidemie in den USA hat 1964 die Geburt von über 20000 Kindern mit kongenitaler Schädigung nach sich gezogen, dies obwohl eine intrauterine Erkrankung bei einer Rötelninfektion in der Schwangerschaft seit 1941 bekannt ist (19). Die Wahrscheinlichkeit einer Schädigung durch eine Rötelninfektion in der Gravidität liegt bis zur 8 . Woche bei $50 \%$, in der 9.-12. Woche bei $34 \%$ und in der 13. -24 . Woche bei $10 \%$ (42), bzw. nach neueren Statistiken im 1. Monat bei $60 \%$, im 2. Monat be $25 \%$, im 3. Monat bei $9 \%$ und im 4 . Monat bei $4 \%$. Seit 1964 haben die Entwicklungen serologischer Tests und verschiedener Impfstoffe, sowie die damit möglichen Vorsorgemaßnahmen, die Möglichkeit geschaffen, Rötelninfektionen in der Schwangerschaft zu verhindern. Leider ist aber anzunehmen, daß eher die Möglichkeit einer therapeutischen Interruption die Zahl kongenitaler Röteln in den USA auf unter 25 Fälle pro Jahr reduziert (44).

In der Diagnostik der Rötelninfektion bzw. des Immunstatus stehen verschiedene serologische Untersuchungsverfahren zur Verfügung, von denen der Hämagglutinationshemmtest (HHT) der am weitesten verbreitete Test ist. Dem Antikörpertiter im HHT wird z.Zt. die größte Bedeutung zugemessen, wobei die Interpretation der Signifikanz niedriger Rötelnantikörpertiter unterschiedlich ist. Einem Titer von $1: 8$ oder $1: 16 \mathrm{im}$ HHT wird eine fragliche Bedeutung zugesprochen (21), bei einem Titer von $1: 32$ und höher aber ein sicherer Schutz gegen eine Rötelninfektion angenommen. Kann ein Titer von 1:16 in seiner Spezifität durch eine zweite Untersuchung mit einer anderen Methode gesichert werden (Mutterschafts-Richtlinien der Kassenärztlichen Bundesvereinigung 1979 und Merkblatt: Verhütung der Röteln-Embryopathie 1980), dann kann auch bei diesem Titer ein Immunschutz angenommen werden.

Zur Verhinderung einer Rötelninfektion in der Schwangerschaft wird empfohlen, alle Mädchen im Alter von 12 und mehr Jahren, alle Schulkinder, die als Kleinkinder nicht geimpft worden sind und auch alle empfänglichen Frauen zu impfen $(3,9)$.

Die Bedeutung dieser Präventivmaßnahmen, die Einhaltung der Mutterschafts-Richtlinien und die Bedeutung zuverlässiger Antikörperbestimmungen werden durch die Rechtsprechung der letzten Jahre verdeutlicht. Vom Bundesgerichtshof (BGH) ist z.B. ausgeführt worden: „Der Arzt, der die Gefahr der Schädigung eines Ungeborenen während der Frühschwangerschaft, die eine Interruption gerechtfertigt hätte, schuldhaft nicht erkannt hat, haftet gegenüber den Eltern auf Ersatz der Mehraufwendungen" (BGH Urteil vom 18. Januar 1983 - VI ZR. 3114/81 München). Entsprechend dem Zustand einer Patientin und dem Zeitpunkt eines eventuellen Kontaktes müssen daher serologische Untersuchungen durchgeführt werden:

- zur sicheren Festlegung einer Immunität und/oder - zum zuverlässigen Nachweis eines frischen Infektes zu verschiedenen Zeiten nach Kontakt bzw. nach einem verdächtigen Exanthem (32).

Diese kurzen Ausführungen zeigen, welchen Wert eine zuverlässige Rötelndiagnostik im ärztlichen Laboratorium besitzt und wie wichtig eine ausgeprägte interne und externe Qualitätskontrolle zur Sicherung serologischer Ergebnisse ist. Im Rahmen dieses Beitrages soll auf die Ergebnisse der externen Qualitätssicherung während der letzten Jahre eingegangen werden. Die Anforderungen der internen Qualitätssicherung sind in verschiedenen Veröffentlichungen [u.a. Merten 1987 (35)] dargestellt worden.

\section{Methoden zur Rötelnantikörperbestimmung}

Zur Bestimmung von Antikörpern gegen das Rötelnvirus sind seit 1964 verschiedene serologische Tests beschrieben worden, wobei der Hämagglutinationshemmtest (HHT) eine besondere Stellung eingenommen hat. $\mathrm{Ne}$ ben ihm sind inzwischen andere gleichwertige Methoden entwickelt worden.

\section{Hämagglutinationshemmtest (HHT)}

Im HHT agglutiniert das Hämagglutinin des Rötelnvirus bestimmte Erythrozyten, wobei spezifische Antikörper aus Patientenseren diese Agglutination unterbinden. Seit der ersten Veröffentlichung dieses Tests (50) sind mehrere Modifikationen beschrieben worden, in denen sowohl verschiedene Testerythrozyten (u.a. Erythrozyten von 1-3 Tage alten Küken, fixierte Hühnererythrozyten und humane 0-Erythrozyten) als auch verschiedene Absorptionsmedien bzw. Fällungsverfahren (Kaolin, Dextransulfat und Heparinmanganchlorid) vorgeschlagen worden sind. Beim HHT müssen vor dem Testansatz unspezifische Inhibitoren (Lipoproteine) aus dem Patientenserum entfernt werden. Da Kaolin aber neben den Inhibitoren auch pH-abhängig bis zu $60 \%$ der spezifischen IgM - und Ig sowie bis zu 40\% der IgA-Antikörper innerhalb von 5 min absorbiert, kann dies zu niedrigeren, evtl. sogar zu falsch-negativen Resultaten führen (23), dies besonders beim Nachweis spezifischer Antikörper der Klasse IgM (22). Im Gegensatz dazu werden mit Heparinmanganchlorid nur weniger als $10 \%$ der Immunglobuline (33), jedoch nicht alle Lipoproteine wie von Kaolin absorbiert. Werden die Inhibitoren nicht bzw. unvollständig absorbiert, können falsch-positive Reaktionen erzielt 
werden. Modifikationen zur Sicherstellung einer vollständigen Beseitigung von Inhibitoren durch Kontrolltitration mit Sindbis-Virus und damit Vermeidung falsch-positiver Ergebnisse sind von Schneweis (46) beschrieben worden.

Das National Committee for Clinical Laboratory Standards (NCCLS) hat 1975 die Beschreibung einer standardisierten Methode veröffentlicht [Standard for Rubella Hemagglutination Inhibition (41)]. Diese Methode empfiehlt den Einsatz von 1-3 Tage alten Kükenerythrozyten und einer Heparinmanganchloridfällung (7). Eine ähnliche Methode ist in Deutschland als standardisierte Technik zur Durchführung des Röteln-HHT mit Heparinmanganchlorid und Hühner-, Küken- oder humanen 0-rh-negativen Erythrozyten empfohlen worden (1). Dennoch findet auch die Kaolinmethode eine sehr verbreitete Anwendung, nachdem Mertens (36) gezeigt hat, daß diese Methode bei korrekter Anwendung sehr zuverlässige Resultate zeigt.

Auch bei einer weltweiten WHO-Studie sind die Ergebnisse beider Absorptions- bzw. Fällungsmethoden so wenig divergierend gewesen, daß nur mittels Abstimmung der teilnehmenden Laboratorien bei denkbar geringer Mehrheit (5:4) die Heparin- $\mathrm{MnCl}_{2}$ - Methode als Referenzmethode empfohlen worden ist.

\section{Hämolyse-in-Gel-Test (HIG)}

Der HIG ist zum Nachweis von Antikörpern gegen Rötelnvirus von Stannegard et al. (51) erstmals 1975 beschrieben worden. Die Methode beruht darauf, daß sich an mit Röteln-Antigen beschichteten Erythrozyten spezifische Rötelnantikörper anlagern und die Erythrozyten nach Zugabe von Komplement lysiert werden. Der Test wird im Gelmilieu durchgeführt, in dem die mit Antigen beladenen Erythrozyten fixiert sind. Das Ergebnis wird als Durchmesser der Hämolyse um das Serumdepot in Millimeter festgestellt und von einem festzulegenden Durchmesser ab als positiv bewertet.

Die im Rahmen einer Rötelninfektion früh gebildeten Antikörper können mit dieser Methode nicht erfaßt werden; vereinzelt können sogar falsch-negative Ergebnisse auftreten, dennoch eignet sich diese Methode gut als Screeningmethode und für den Nachweis einer früheren Infektion $(20,28)$, was auch ein Vergleich mit dem von Mertens als optimal ermittelten HHT gezeigt hat (62).

\section{Passiver Hämagglutinationstest (PHA)}

Dieser Test ist in den USA nur zur Testung des Immunstatus zugelassen, da Rötelnantikörper in diesem Test erst 4 bis 5 Wochen nach einer klinischen Erkrankung nachweisbar werden (8). Schneweis (47) hat 1979 beschrieben, daß Antikörper im PHA erst 6 bis 8 Wochen nach dem Exanthem nachweisbar sind. Beim PHA wird das Rötelnvirus an Aldehyd-behandelte Hühnererythrozyten absorbiert und als Antigen gegen die spezifischen Antikörper im Patientenserum eingesetzt. Antikörper agglutinieren diese Erythrozyten. Ein Vorteil der Methode besteht darin, daß das Patientenserum vor dem Test weder verdünnt noch von unspezifischen Agglutininen befreit werden muß; dennoch hat sich der PHA in Deutschland im Gegensatz zu seiner weiten Verbreitung in den USA nicht durchsetzen können.

\section{Enzym-Immuno-Assay (EIA)}

Enzym-Immuno-Assays bei viralen Erkrankungen sind von Bidwell (4) und von Gravell (18) 1977 für den Nach- weis von Rötelnantikörpern beschrieben worden. Rötelnantigen wird unspezifisch auf einer festen Phase absorbiert, so daß sich spezifische Antikörper im Patientenserum an dieses Antigen anlagern können.

Nach entsprechenden Waschungen wird ein enzymkonjugiertes Antihuman-lgG hinzugesetzt, das, falls es sich an die bereits gebundenen IgG-Antikörper anlagern kann, z.B. die Umsetzung von farblosem $p$-Nitrophenylphosphat in gelbes p-Nitrophenol bewirkt. Die Menge des entstandenen $p$-Nitrophenols ist dem Rötelnantikörpergehalt proportional und kann in einem Photometer gegen ein WHO-Referenzpräparat gemessen werden. Vergleichende Untersuchungen der Empfindlichkeit von EIA und HHT sind von Doerr et al. (13) und Enders et al. $(14,15)$ beschrieben worden. EIA und HHT können theoretisch als gleichwertig betrachtet werden $(29,59)$, die Erfahrung zeigt jedoch, daß in der Routine der EIA mit größerer Unsicherheit behaftet ist (siehe später).

\section{Radio-Immuno-Assay (RIA)}

Beim RIA ist im Gegensatz zum ElA das Antihumanglobulin nicht mit einem Enzym, sondern mit einem radioaktiven Isotop markiert, dessen Aktivität direkt gemessen werden kann, ohne daß die Umsetzung eines Substrates als weitere Reaktion erforderlich ist. RIAs sind von Kalimo (25) und Sugishita (52) beschrieben worden.

\section{Fluoreszenz-Immuno-Assay (FIA)}

Das Prinzip des Fluoreszenz-Immuno-Assay ist dem des EIA und dem des RIA ähnlich. Im Gegensatz zum EIA wird auch hier wie im RIA nicht der Umsatz eines Substrates gemessen, sondern das an den Antikörper gekoppelte Fluorescein wird nach Anregung durch UV-Licht direkt gemessen. Dieser Test ist schon früh von Lennette (30) mit der KBR und dem Neutralisationstest verglichen worden. Schilt (45) und erneut Frisch (16) haben ihn als Alternative (FIAX) zum Hämagglutinationshemmtest beschrieben. In Deutschland hat er bisher keine breitere Verwendung gefunden.

\section{Komplement-Bindungs-Reaktion (KBR)}

Das Prinzip dieses Tests beruht auf einer Hämolyse der mit Antikörpern beladenen Erythrozyten in Anwesenheit von Komplement. Wird dieses Komplement aus dem Ansatz durch eine vorher abgelaufene Reaktion zwischen spezifischen Antikörpern und einem Rötelnantigen gebunden, unterbleibt die Hämolyse der Indikatorerythrozyten.

In diesem Test werden bei geringer Empfindlichkeit in erster Linie IgG-Antikörper nachgewiesen, und dies eine Woche später als im HHT. Der Abfall des positiven Antikörpernachweises in der KBR nach Infektion ist unterschiedlich, er kann einige Jahre dauern. Ein Titer von über $1: 32$ weist je nach Testart eventuell eine frische Infektion in den letzten 12 Monaten nach. Niedrige Titer unter 1:32 können auf eine frühere Infektion hinweisen, sollten aber mit Zurückhaltung bewertet werden (39).

\section{Latex-Agglutinations-Test (LAT)}

Dieser Test, der auf dem Prinzip der Agglutination von mit Rötelnantigèn beladenen Latexpartikeln durch spezifische Antikörper beruht, wird in Deutschland kaum, zunehmend jedoch in den USA, eingesetzt. Der LAT ist von Meegan (34) beschrieben und dem HHT und ELISA als 
gleichwertig bezeichnet worden. Da jedoch positive Latexergebnisse auch bei negativem HHT gefunden werden, sind Interpretationen und damit der Einsatz dieses Testes mit Zurückhaltung zu bewerten.

\section{Nachweis rötelnspezifischer Antikörper der Klasse IgM}

Die besondere Bedeutung für den zuverlässigen Nachweis von spezifischen IgM-Antikörpern gegen Rötelnantigen ist aus den Folgen für das ungeborene Kind deutlich. Für den Nachweis sind neben der klassischen Referenzmethode, der Saccharose-Dichtegradienten-Zentrifugationsmethode (SDZ), auch andere Trennungsverfahren für $\lg$ und $\lg M(12,55,61)$ sowie auch direkte Nachweisverfahren mittels EIA, RIA und FIA $(11,24)$ sowie der SPIT (27) entwickelt worden. Das Prinzip der SDZ beruht auf der Trennung der verschiedenen Ig-Klassen über einen Saccharose-Dichtegradienten (10-38\% Saccharose) in der Ultrazentrifuge (z.B. $24 \mathrm{Std}$. bei $150000 \times \mathrm{g}$ bei $4^{\circ} \mathrm{C}$ ). Die Fraktionen werden anschließend kontinuierlich selektiv gesammelt und einzeln im HHT auf ihren Antikörpergehalt gegen Rötelnvirus getestet. Sind die IgM-enthaltenden Fraktionen IgG-frei und bewirken sie eine Hämagglutinationshemmung, wird dies als positiver Nachweis für rötelnspezifische Antikörper der Klasse IgM gewertet.

Die verschiedenen Methoden zum Nachweis von rötelnspezifischen IgM-Antikörpern sind von Lindenschmidt (31) in einer vergleichenden Studie untersucht worden. Hierbei haben sich im ELISA und im SPIT 7\% unspezifisch-positive Resultate nachweisen lassen, so daß bei der Fragestellung Interruptio eine weitere Verwendung der SDZ zusätzlich gefordert wird. Im SPIT ist von den Autoren eine Spezifität von 100\% bei einer Empfindlichkeit von lediglich 27\%, im ELISA bei frischen Röteln eine Empfindlichkeit von 85\%, bei Schwangeren mit hohem Antikörpertiter von $63 \%$ und bei Vorliegen einer Rötelnembryopathie von $53 \%$ gefunden worden. Andere Studien haben gezeigt, daß verschiedene Tests zum Nachweis von Röteln-IgM-Antikörpern diese über unterschiedlich lange Zeiträume nachweisen können, wobei eine hohe Empfindlichkeit des Tests über einen zu langen Zeitraum zu einem positiven Nachweis von spezifischen IgM-Antikörpern führt und damit wenig geeignet für den Nachweis einer kürzlichen Infektion ist.

So wie ein positiver, ist auch ein negativer Nachweis rötelnspezifischer Antikörper der Klasse IgM mit Vorsicht zu bewerten, da er eine kürzliche Infektion nicht sicher ausschließt $(38,57)$. Auch ein negativer rötelnspezifischer IgM-Nachweis im Nabelschnurblut schließt eine kongenitale Rötelninfektion nicht sicher aus (58), so daß die Wertigkeit eines IgM-Screeningtests auf konnatale Röteln (43) mit dieser Einschränkung gesehen werden muß. Es wird empfohlen, bei der Frage einer Interruptio neben der ausführlichen Anamnese zwei verschiedene Methoden zum IgM-Nachweis durchzuführen (37).

Aus diesen Darstellungen und der zitierten Literatur ergibt sich zusammengefaßt folgendes Bild:

- Der HHT gilt als Primärtest zum Nachweis von Rötelnantikörpern.

- EIA, RIA und FIA können für den Nachweis von IgGAntikörpern gleichartige Informationen geben.

- Der HIG sollte als Bestätigungstest, der PHA nur zur Klärung des Immunstatus eingesetzt werden; beide sind leicht durchzuführen und zeigen zuverlässige Ergebnisse.
- Die KBR wird kaum noch, der LAT noch nicht eingesetzt.

- Der Nachweis spezifischer IgM-Antikörper ist der Klärung einer frischen Infektion in der Schwangerschaft bzw. einer kongenitalen Infektion vorbehalten und solite durch mindestens zwei Methoden geführt werden.

\section{Externe Qualitätssicherung}

Nach mehreren Pilot-Ringversuchen der Deutschen Vereinigung zur Bekämpfung der Viruskrankheiten (DVV), des Institutes für Standardisierung und Dokumentation im medizinischem Laboratorium e. V. (INSTAND) und des Center for Diseases Control (CDC) in den USA sind Röteln-Ringversuche in den USA vom College of American Pathologists (CAP) 1978 und von INSTAND 1979 in Deutschland als Routine Ringversuche eingeführt worden.

In einem CDC-Ringversuch 1977 haben von 298 teilnehmenden Laboratorien 35 (11,7\%) einen negativen Rötelnantikörper nicht richtig und über $50 \%$ bei einem hohen Rötelnantikörpertiter kein vergleichbares Ergebnis mitgeteilt (53). 1980 hat,ein weiterer Ringversuch bessere Ergebnisse bei der Bestimmung negativer Rötelnseren gezeigt (54), was sich auch in den Ringversuchen des College of American Pathologists (10) zwischen 1978 und 1980 mit einer Übereinstimmung der Teilnehmerergebnisse von über $90 \%$ bestätigt hat. In diesen Ringversuchen zeigt sich eine Bevorzugung des PHA bei einem Anstieg von 29,9\% auf $51 \%$ der Teilnehmer. Die Anwendung des HHT unter Einsatz von fixierten Hühnererythrozyten und der Kaolinabsorptionsmethode ist von 26,4 auf $12,2 \%$ abgesunken, während der HHT mit humanen 0 -Erythrozyten und Heparin- $\mathrm{MnCl}_{2}$-fällung von 9,5 auf $15,2 \%$ angestiegen ist. 1 bis 3 Tage alte Kükenerythrozyten werden relativ selten $(2,5$ bis $6,4 \%)$ eingesetzt. Die Verwendung der Methoden mittels fixierter Hühnererythrozyten bei Kaolinabsorption (in den Ringversuchen 1978 mit 21 bis $46,4 \%$ die am häufigsten durchgeführte HHT-Methode) ist in den Ringversuchen 1980 auf 12,2 bis $14,6 \%$ abgesunken, während humane 0 -Erythrozyten bei Heparin- $\mathrm{MnCl}_{2}$-fällung eine leichte Zunahme von 9,5 bis $13 \%$ (1978), auf 12,6 bis $15,2 \%$ (1980) aufweisen. Der PHA ist die am häufigsten angewandte Methode (1978: 34 bis $51 \%, 1980$ : 29,9 bis $46,6 \%$ ). Eine Zusammenfassung dieser Ringversuchsergebnisse ist von Skendzel 1981 (48) veröffentlicht worden. Zusammenfassend stellt er fest, daß $47 \%$ der Teilnehmer den PHA, 45\% den $\mathrm{HHT}, 7 \%$ den indirekten Fluoreszenz-Assay und weniger als $1 \%$ den Enzym-Immuno-Assay eingesetzt haben.

Wegen der damals geringen Beteiligung im EIA ist diese Methode nicht bewertet worden. Die beiden anderen Methoden haben Empfindlichkeiten und Spezifitäten von über $94 \%$ bzw. $88 \%$ aufgewiesen. Skendzel (49) berichtet später über die Methodenverteilung bei CAP-RötelnRingversuchen 1983: HHT 8\%, PHA 31\%, Latex Agglutination $25 \%$, EIA $24 \%$, indirekte Immunfluoreszenz $10 \%$ und RIA $2 \%$. Dies weist auf einen deutlichen Anstieg des EIA, noch betonter der Latex-Agglutination bei Rückgang des PHA und deutlichem Rückgang der HHT-Anwendung in den USA hin.

INSTAND hat seit November 1979 zur Bestimmung von Antikörpern gegen das Rötelnantigen 11 Ringversuche unter Einsatz von 22 Proben durchgeführt. In allen Ringversuchen sind Originalseren von freiwilligen Spendern 
zum Teil vor und nach aktiver Rötelnimpfung eingesetzt worden. Die Seren sind mittels geschlossenem Abnahmesystem in Blutbeuteln (Blood-pack, Fa. Travenol) entnommen und nach Gerinnung in diesen zentrifugiert worden; das so gewonnene Serum ist in Mengen von 1 bis $2 \mathrm{ml}$ steril abgefüllt und bis zur Versendung bei $-80^{\circ} \mathrm{C}$ eingefroren worden. Der Versand ist wie der normaler Patientenproben erfolgt.

Die Teilnehmerzahl an den Rötelnringversuchen hat sich seit 1979 etwa verdoppelt, ist aber mit 81 teilnehmenden Laboratorien im Mai 1985 immer noch gering. Alle Teilnehmer haben Ergebnisse für den Hämagglutinationshemmtest mitgeteilt, sie sind in Tab. 1 aufgelistet. Bei 36 bis 81 Teilnehmern je Ringversuch ergibt sich zusammenfassend folgendes Bild: Bei 7 negativen Proben finden sich 1.9 bis $4.8 \%$ falsch-positive Ergebnisse, wenn ein Titer von $1: 16$ als Grenze angesetzt wird. Wird aber eine

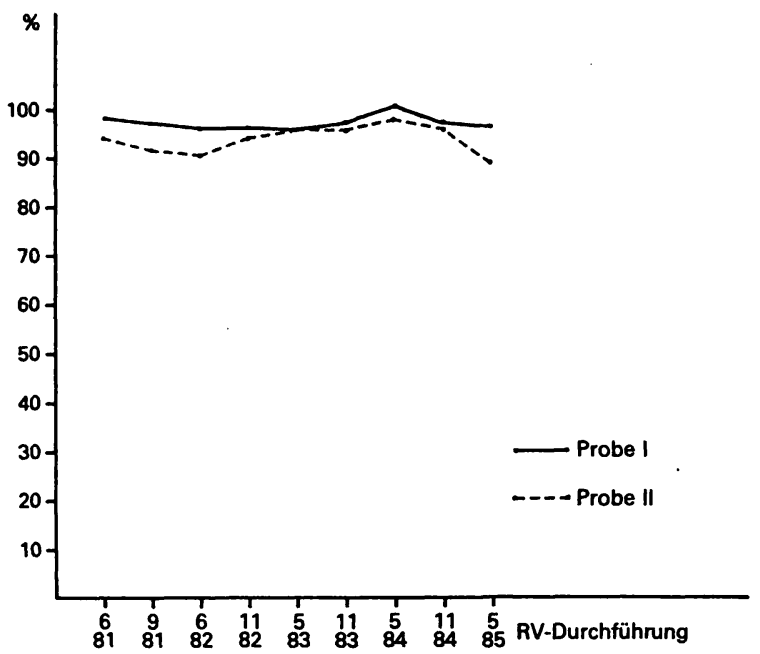

Abb. 1: Teilnehmer in Prozent, die in INSTAND-Ringversuchen für den Röteln-Hämagglutinationshemmtest (HHT) Ergebnisse innerhalb der jeweils festgelegten Titerbereiche mitgeteilt haben.
Grenze von 1:8 als Grenztiter angegeben, finden sich in $5,6 \%$ bis $24,5 \%$ falsch-positive Ergebnisse. Für grenzwertig positive Seren haben bei einer Grenze von unter 1:8 7,1 bis $22,5 \%$, bei einer Grenze von unter $1: 16$ sogar 35,6 bis $46,9 \%$ der Teilnehmer falsch-negative Ergebnisse mitgeteilt.

In den Ringversuchen der Jahre 1981 bis 1985 ist die Anzahl der Fehlbestimmungen bei grenzwertigen Proben deutlich abgesunken, falsch-negative Werte sind noch in 1,2 bis $5,1 \%$ mitgeteilt worden. In drei Ringversuchen haben alle von den Teilnehmern mitgeteilten Titer oberhalb $1: 8$ gelegen. Positive Ergebnisse zeigen in der Regel eine Streuung von -1 bis +2 , vereinzelt von -2 bis +3 Titerstufen auf. Innerhalb eines zulässigen Bereiches von \pm einer Titerstufe liegen in den Ringversuchen seit 1981 bei positiven Seren 88,5 bis $97,3 \%$ bei negativen Seren 95,2 bis $100 \%$ der Teilnehmerergebnisse (Abb. 1 ).

$\mathrm{Zu}$ vergleichbaren Zahlen hat auch eine Pilotstudie geführt, bei der in 8 verschiedenen Laboratorien 10 Seren je $5 \mathrm{mal}$ im gleichen Testsystem austitriert worden sind, wobei gleichzeitig als Vergleichsserum das 2. WHO-AntiRöteln-Referenzserum (Staatliches Seruminstitut Kopenhagen) eingesetzt worden ist. Die Ergebnisse zeigen in der Regel eine Schwankung von \pm 1 Titerstufe, wenn der Test im gleichen Labor durchgeführt wird $(3 \times 1: 32$ bis $1: 128 ; 1 \times 1: 16$ bis $1: 64$ und $1 \times 1: 128$ bis $1: 512$ ); auch bei einem Vergleich der Titer von Labor zu Labor zeigt sich in der Regel eine Schwankung von \pm 1 Titerstufe $(1: 32$ bis $1: 128,1: 128$ bis $1: 512,1: 16$ bis $1: 64$ und $1: 64$ bis $1: 256)$; in einem Fall von $1: 16$ bis $1: 128$ (17).

Aus den Mitteilungen der Teilnehmer über die jeweils verwendeten Erythrozyten ist ersichtlich, daß Hammelund humane 0 -Erythrozyten am häufigsten, gefolgt von Küken-Erythrozyten, verwendet werden. Taubenerythrozyten werden heute so gut wie nicht mehr von den Teilnehmern eingesetzt. Die Mitteilungen der Teilnehmer über die jeweils eingesetzten Antigene zeigen, daß über 90\% der Laboratorien Antigene von drei Herstellern verwenden, wobei eine Unterscheidung nach Einzelantigenen bzw. Kit mit Antigen nicht erfolgt. Die am häufigsten eingesetzten Antigene sind in den Fertigtestprodukten

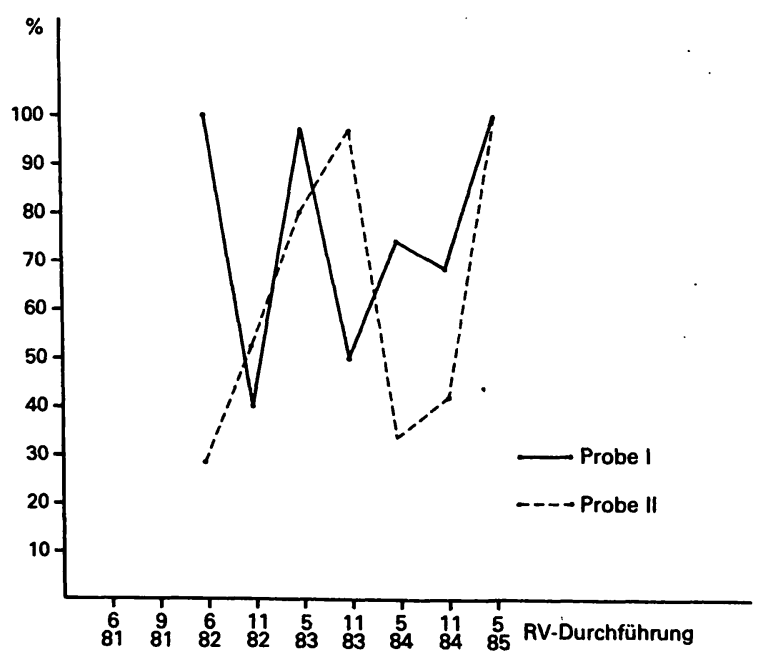

Abb. 2: Teilnehmer in Prozent, die in INSTAND-Ringversuchen für den Röteln-Hämolyse-in-Gel-Test (HIG) Ergebnisse innerhalb der jeweils festgelegten Titerbereiche mitgeteilt haben.

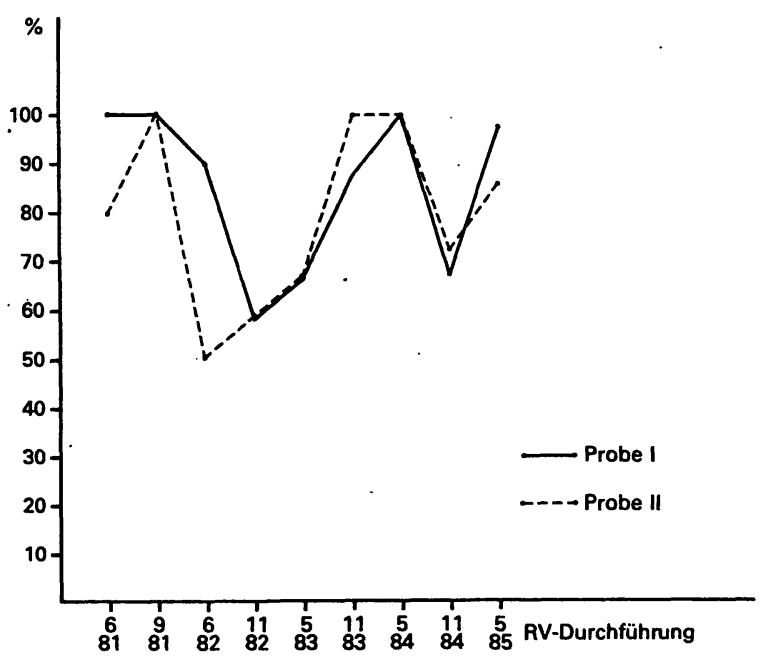

Abb. 3: Teilnehmer in Prozent, die in INSTAND-Ringversuchen für dén Röteln-Enzym-Immun-Assay (EIA) Ergebnisse innerhalb der jeweils festgelegten Titerbereiche mitgeteilt haben. 
Tab. 1: Ergebnisse der Teilnehmer für den Hämagglutinationshemmtest (HHT) in INSTAND-Röteln-Ringversuchen $1979-1985$

\begin{tabular}{|c|c|c|c|c|c|c|c|c|c|c|c|}
\hline \multicolumn{2}{|c|}{ Ringversuch } & \multirow[b]{2}{*}{$\begin{array}{l}\% \\
\text { Probe } 51\end{array}$} & \multirow{2}{*}{$\frac{1:<8}{7,1}$} & \multirow{2}{*}{$\begin{array}{l}1: 8 \\
28,6 \\
12\end{array}$} & \multirow{2}{*}{$\begin{array}{l}1: 16 \\
40,5 \\
17\end{array}$} & \multirow{2}{*}{$\frac{1: 32}{\underset{21.4}{9}}$} & \multirow{2}{*}{$\frac{1: 64}{2,4}$} & \multirow{2}{*}{$\frac{1: 128}{0}$} & \multirow{2}{*}{$\begin{array}{l}1: 256 \\
0\end{array}$} & \multirow{2}{*}{$\frac{1: 512}{0}$} & \multirow{2}{*}{$\frac{n}{42}$} \\
\hline Nov. & 79 & & & & & & & & & & \\
\hline \multirow[t]{2}{*}{ Sept. } & 80 & $\begin{array}{l}\% \\
\text { Probe } 09\end{array}$ & $\begin{array}{l}22,5 \\
11\end{array}$ & $\begin{array}{l}24,5 \\
12\end{array}$ & $\begin{array}{l}40,8 \\
20\end{array}$ & $\begin{array}{c}10,2 \\
5\end{array}$ & $\begin{array}{l}2,0 \\
1\end{array}$ & 0 & 0 & 0 & 49 \\
\hline & & $\begin{array}{l}\text { Probe } 08 \\
\%\end{array}$ & $\begin{array}{l}47 \\
92,0\end{array}$ & $\begin{array}{l}2 \\
4,0\end{array}$ & $\begin{array}{l}2 \\
4,0\end{array}$ & 0 & 0 & 0 & 0 & 0 & 51 \\
\hline \multirow[t]{2}{*}{ Juni } & 81 & $\begin{array}{l}\% \\
\text { Probe } 01\end{array}$ & $\begin{array}{l}98,1 \\
51\end{array}$ & 0 & 0 & 0 & 0 & 0 & 0 & 1,9 & 52 \\
\hline & & $\begin{array}{l}\text { Probe } 02 \\
\%\end{array}$ & 0 & 0 & $\begin{array}{l}5 \\
9,7\end{array}$ & $\begin{array}{l}30 \\
57,7\end{array}$ & $\begin{array}{l}14 \\
26,9\end{array}$ & $\begin{array}{l}2 \\
3,8 \\
\end{array}$ & 0 & $\begin{array}{l}1 \\
1,9\end{array}$ & 52 \\
\hline \multirow[t]{2}{*}{ Sept. } & 81 & $\begin{array}{l}\% \\
\text { Probe } 04 \\
\end{array}$ & $\begin{array}{l}94,4 \\
34\end{array}$ & $\begin{array}{l}2,8 \\
1\end{array}$ & 0 & 0 & 0 & $\begin{array}{l}2,8 \\
1\end{array}$ & 0 & 0 & 36 \\
\hline & & $\begin{array}{l}\text { Probe } 05 \\
\%\end{array}$ & $\begin{array}{l}1 \\
2,8\end{array}$ & 0 & 0 & $\begin{array}{l}11 \\
30,6\end{array}$ & $\begin{array}{l}16 \\
44,4\end{array}$ & $\begin{array}{c}6 \\
16,6\end{array}$ & $\begin{array}{l}2 \\
5,6\end{array}$ & 0 & 36 \\
\hline \multirow[t]{2}{*}{ Juni } & 82 & $\begin{array}{l}\% \\
\text { Probe } 04\end{array}$ & $\begin{array}{l}86,2 \\
44\end{array}$ & $\begin{array}{l}9,8 \\
5\end{array}$ & $\begin{array}{l}2,0 \\
1\end{array}$ & 0 & 0 & 0 & $\begin{array}{l}2,0 \\
1\end{array}$ & 0 & 51 \\
\hline & & $\begin{array}{l}\text { Probe } 05 \\
\%\end{array}$ & 0 & 0 & $\begin{array}{l}3 \\
5,8\end{array}$ & $\begin{array}{l}14 \\
27,5\end{array}$ & $\begin{array}{l}24 \\
47,1 .\end{array}$ & $\begin{array}{l}8 \\
15.7\end{array}$ & $\begin{array}{l}2 \\
3,9\end{array}$ & 0 & 51 \\
\hline \multirow[t]{2}{*}{ Nov. } & 82 & $\begin{array}{l}\% \\
\text { Probe } 10\end{array}$ & $\begin{array}{l}2,0 \\
1 \\
\end{array}$ & $\begin{array}{l}2,0 \\
1 \\
\end{array}$ & $\begin{array}{l}52,0 \\
26\end{array}$ & $\begin{array}{l}40,0 \\
20\end{array}$ & $\begin{array}{l}4,0 \\
2 \\
\end{array}$ & 0 & 0 & 0 & 50 \\
\hline & & $\begin{array}{l}\text { Probe } 11 \\
\%\end{array}$ & $\begin{array}{l}1 \\
2,0\end{array}$ & 0 & $\begin{array}{l}2 \\
4,0\end{array}$ & $\begin{array}{l}13 \\
26,0\end{array}$ & $\begin{array}{l}29 \\
58,0\end{array}$ & $\begin{array}{c}5 \\
10,0\end{array}$ & 0 & 0 & 50 \\
\hline \multirow[t]{2}{*}{ Mai } & 83 & $\begin{array}{l}\% \\
\text { Probe } 21 \\
\end{array}$ & 0 & 0 & 0 & $\begin{array}{l}26,4 \\
19 \\
\end{array}$ & $\begin{array}{l}47,2 \\
34 \\
\end{array}$ & $\begin{array}{l}22,2 \\
16\end{array}$ & $\begin{array}{l}4,2 \\
3\end{array}$ & 0 & 72 \\
\hline & & $\begin{array}{l}\text { Probe } 22 \\
\%\end{array}$ & 0 & $\begin{array}{l}2 \\
2,9\end{array}$ & $\begin{array}{l}31 \\
45,6\end{array}$ & $\begin{array}{l}26 \\
38,2\end{array}$ & $\begin{array}{c}8 \\
11,8\end{array}$ & $\begin{array}{l}1 \\
1,5\end{array}$ & 0 & 0 & 68 \\
\hline \multirow[t]{2}{*}{ Nov. } & 83 & $\begin{array}{l}\% \\
\text { Probe } 41\end{array}$ & 0 & $\begin{array}{l}1.6 \\
1\end{array}$ & $\begin{array}{l}31,3 \\
20\end{array}$ & $\begin{array}{l}46,8 \\
30\end{array}$ & $\begin{array}{l}18,7 \\
12\end{array}$ & $\begin{array}{l}1,6 \\
1\end{array}$ & 0 & 0 & 64 \\
\hline & & $\begin{array}{l}\text { Probe } 42 \\
\%\end{array}$ & $\begin{array}{l}53 \\
84,1\end{array}$ & $\begin{array}{c}7 \\
11,1\end{array}$ & $\begin{array}{l}2 \\
3,2 \\
\end{array}$ & 0 & $\begin{array}{l}1 \\
1,6\end{array}$ & 0 & 0 & 0 & 63 \\
\hline \multirow[t]{2}{*}{ Mai } & 84 & $\begin{array}{l}\% \\
\text { Probe } 21 \\
\end{array}$ & $\begin{array}{l}90,9 \\
70\end{array}$ & $\begin{array}{l}9,1 \\
7 \\
\end{array}$ & 0 & 0 & 0 & 0 & 0 & 0 & 77 \\
\hline & & $\begin{array}{l}\text { Probe } 22 \\
\%\end{array}$ & 0 & 0 & $\begin{array}{c}9 \\
12,3\end{array}$ & $\begin{array}{l}43 \\
58,9\end{array}$ & $\begin{array}{l}19 \\
26,0\end{array}$ & $\begin{array}{l}1 \\
1,4 \\
\end{array}$ & $\begin{array}{l}1 \\
1,4\end{array}$ & 0 & 73 \\
\hline \multirow[t]{2}{*}{ Nov. } & 84 & $\begin{array}{l}\% \\
\text { Probe } 41\end{array}$ & 0 & 1,5 & $\begin{array}{l}47.75 \\
31 \\
\end{array}$ & $\begin{array}{l}47,75 \\
31 \\
\end{array}$ & $\begin{array}{l}1,5 \\
1\end{array}$ & $\begin{array}{l}1,5 \\
1\end{array}$ & 0 & 0 & 65 \\
\hline & & $\begin{array}{l}\text { Probe } 42 \\
\%\end{array}$ & 0 & $\begin{array}{l}1 \\
1,5 \\
\end{array}$ & $\begin{array}{l}1 \\
1,5\end{array}$ & $\begin{array}{l}23 \\
34,9\end{array}$ & $\begin{array}{l}33 \\
50,0\end{array}$ & $\begin{array}{c}7 \\
10,6\end{array}$ & $\begin{array}{l}1 \\
1,5\end{array}$ & 0 & 66 \\
\hline \multirow[t]{3}{*}{ Mai } & 85 & $\begin{array}{l}\% \\
\text { Probe } 21 \\
\end{array}$ & $\begin{array}{l}75,4 \\
61 \\
\end{array}$ & $\begin{array}{l}21,0 \\
17 \\
\end{array}$ & $\begin{array}{l}1,2 \\
1 \\
\end{array}$ & $\begin{array}{l}1,2 \\
1\end{array}$ & 0 & $\begin{array}{l}1,2 \\
1\end{array}$ & 0 & 0 & 81 \\
\hline & & $\begin{array}{l}\text { Probe } 22 \\
\%\end{array}$ & $\begin{array}{l}4 \\
5,1\end{array}$ & 0 & $\begin{array}{l}2 \\
2,6 \\
\end{array}$ & $\begin{array}{l}25 \\
32,1\end{array}$ & $\begin{array}{l}32 \\
41,0\end{array}$ & $\begin{array}{l}12 \\
15,4\end{array}$ & $\begin{array}{l}3 \\
3,8\end{array}$ & 0 & 78 \\
\hline & & $\begin{array}{l}\text { Probe } 23 \\
\%\end{array}$ & $\begin{array}{l}1 \\
1,2\end{array}$ & 0 & $\begin{array}{l}3 \\
3,7\end{array}$ & $\begin{array}{l}26 \\
32,1\end{array}$ & $\begin{array}{l}34 \\
42,0\end{array}$ & $\begin{array}{l}14 \\
17,3\end{array}$ & $\begin{array}{l}3 \\
3,7\end{array}$ & 0 & 81 \\
\hline
\end{tabular}

der Firmen enthalten, zwei Hersteller geben ihr Antigen auch einzeln ab. Eine überwiegende Anwendung von Fertigtestsätzen ist aber wahrscheinlich.

In Tab. 2 sind die Ergebnisse aller Ringversuche in bezug auf die Teilnehmerzahl und die Bestehensquote aufgelistet. Sollwerte und Streuung sind weitgehend durch Re- ferenzlaboratorien ermittelt. Wo dies nicht möglich gewesen ist, sind Sollwerte und Streuung aus der Grundgesamtheit ermittelt worden. Extrem abweichende Werte (Ausreißer) sind dabei nicht berücksichtigt worden.

Im Gegensatz zum HHT, für den von allen Teilnehmern Ergebnisse mitgeteilt wordén sind, ist der HIG anfangs 
nur von $26,9 \%$, später von $50 \%$ der Teilnehmer eingesetzt worden. Auch der EIA ist anfangs nur von 5,4 bis $9,4 \%$, später von 58,5 bis $61,2 \%$ eingesetzt worden. Die Bestimmung rötelnspezifischer Antikörper der Klasse IgM ist gleichfalls in ihrer Anwendungshäufigkeit von 16\% auf $57.9 \%$ angestiegen.

Im HIG haben für die negativen Proben 74,2 bis $100 \%$, für die positiven Proben 28.5 bis $97,6 \%$ der Teilnehmer richtige Ergebnisse berichtet (Abb. 2). Wegen der bis einschließlich 1984 aber geringen Teilnehmerzahl ist diese Ergebnisauswertung nur unter Vorbehalt zu werten.

Im ElA haben für die negativen Proben 90 bis $100 \%$, für die positiven Proben 50 bis $100 \%$ der Teilnehmer richtige Ergebnisse berichtet (Abb.3). Auch hier ist zu berücksichtigen, daß bis einschließlich 1983 die geringe Teilnehmerzahl eine statistische Auswertung in ihrer Aussage einschränkt.

Für die Bestimmung rötelnspezifischer Antikörper der Klasse IgM ist die Bewertung der Ergebnisse in „bestanden/nicht bestanden" ebenfalls unter Vorbehalt zu sehen, da es sich um Seren nach erfolgter Rötelnimpfung handelt. In diesen Seren liegen Röteln-IgM-Antikörper nur in geringen Konzentrationen vor. In IgM-negativen Seren sind zwischen 80 und $100 \%$, in fünf IgM-positiven Seren zwischen $38,4 \%$ und $92,5 \%$ richtige Ergebnisse mitgeteilt worden (bei einer ansteigenden Beteiligung von 16\% auf
57,9\%). Auf die Probleme der klinischen Wertung und des Einsatzes von verschiedenen Methoden bei schwach positivem Röteln-IgM-Nachweis, wie er in Impfseren anzutreffen sein kann, ist vorne schon näher eingegangen worden; sie müssen bei der Bewertung dieser Ringversuchsergebnisse berücksichtigt werden.

\section{Diskussion}

Die seit 1979 von INSTAND durchgeführten Rötelnringversuche zeigen, daß in erster Linie der Hämagglutinationshemmtest für die Primärdiagnostik und der EIA oder HIG als Bestätigungstest eingesetzt werden. Die zur Bestimmung des Immunstatus in den USA weit verbreiteten PHA und Latex-Agglutinationstests finden hier kaum Anwendung.

In den Mutterschafts-Richtlinien der KBV wird unabhängig von der Methode bei einem Titer von 1:32 im HHT ein Immunschutz festgeschrieben und bei einem Titer von 1:16, wenn die Spezifität durch eine zweite Methode bestätigt wird. Eine solche Festlegung bedingt für Rötelnringversuche eine strikte Bewertung der Titerhöhe im $\mathrm{HHT}$, ohne Berücksichtigung von Methodenmodifikationen, der eingesetzten Antigene oder der verwendeten Erythrozyten.

Tab. 2: Aufschlüsselung der Teilnehmer an INSTAND-Röteln-Ringversuchen entsprechend Gesamt-Teilnehmerzah/ und Ergebnismitteilung für die einzelnen Testarten wie auch Anzahl der Ergebnisse, die innerhalb der jeweils festgelegten Bereiche liegen (geringfügige Unterschiede der Prozentangaben „Bestanden” "beim HHT gegenüber Tab. 1 ergeben sich durch die jeweilige Rundung von Teilnehmerergebnissen in Tab. 1)

\begin{tabular}{|c|c|c|c|c|c|c|c|c|c|c|c|c|c|c|c|}
\hline & \multirow{2}{*}{$\begin{array}{l}\begin{array}{l}\text { Nov. } 79 \\
\text { Probe }\end{array} \\
51\end{array}$} & \multicolumn{2}{|c|}{$\begin{array}{l}\text { Sept. } 80 \\
\text { Probe }\end{array}$} & \multicolumn{2}{|c|}{$\begin{array}{l}\text { Juni } 81 \\
\text { Probe }\end{array}$} & \multicolumn{2}{|c|}{$\begin{array}{l}\text { Sept. } 81 \\
\text { Probe }\end{array}$} & \multicolumn{2}{|c|}{$\begin{array}{l}\text { Juni } 82 \\
\text { Probe }\end{array}$} & \multicolumn{2}{|c|}{$\begin{array}{l}\text { Nov. } 82 \\
\text { Probe }\end{array}$} & \multicolumn{2}{|c|}{$\begin{array}{l}\text { Mai } 83 \\
\text { Probe }\end{array}$} & \multicolumn{2}{|c|}{$\begin{array}{l}\text { Nov. } 83 \\
\text { Probe }\end{array}$} \\
\hline & & 07 & 08 & 01 & 02 & 04 & 05 & 04 & 05 & 10 & 11 & 21 & 22 & 41 & 42 \\
\hline $\begin{array}{l}\text { Ges. TN n } \\
\text { Beteiligung } \% \\
\text { Bestanden } n \\
\\
\end{array}$ & $\begin{array}{c}42 \\
100 \\
38 \\
90,5\end{array}$ & $\begin{array}{c}49 \\
100 \\
37 \\
75,5\end{array}$ & $\begin{array}{c}51 \\
100 \\
49 \\
96,1\end{array}$ & $\begin{array}{c}52 \\
100 \\
51 \\
98,1\end{array}$ & $\begin{array}{c}52 \\
100 \\
49 \\
94,2\end{array}$ & $\begin{array}{c}36 \\
100 \\
35 \\
97,2\end{array}$ & $\begin{array}{c}36 \\
100 \\
33 \\
91,7\end{array}$ & $\begin{array}{l}51 \\
100 \\
49 \\
96,1\end{array}$ & $\begin{array}{c}51 \\
100 \\
46 \\
90,2\end{array}$ & $\begin{array}{c}50 \\
100 \\
48 \\
96,0\end{array}$ & $\begin{array}{c}50 \\
100 \\
47 \\
94,0\end{array}$ & $\begin{array}{c}72 \\
100 \\
69 \\
95,8\end{array}$ & $\begin{array}{c}68 \\
100 \\
65 \\
95,6\end{array}$ & $\begin{array}{c}64 \\
100 \\
62 \\
96,8\end{array}$ & $\begin{array}{c}63 \\
100 \\
60 \\
95,2\end{array}$ \\
\hline
\end{tabular}

HIG

\begin{tabular}{|c|c|c|c|c|c|c|c|c|c|}
\hline $\begin{array}{l}\text { TN } \\
\text { Beteiligung } \\
\text { Bestanden }\end{array}$ & $\begin{array}{l}\mathrm{n} \\
\% \\
\mathrm{n} \\
\%\end{array}$ & $\begin{array}{c}14 \\
27,5 \\
14 \\
100\end{array}$ & $\begin{array}{c}14 \\
27,5 \\
4 \\
28,5\end{array}$ & $\begin{array}{l}20 \\
40,0 \\
8 \\
40,0\end{array}$ & $\begin{array}{l}21 \\
42,0 \\
11 \\
52,9\end{array}$ & $\begin{array}{l}36 \\
50,0 \\
35 \\
97,2\end{array}$ & $\begin{array}{l}36 \\
52,9 \\
29 \\
80,5\end{array}$ & $\begin{array}{l}36 \\
56,3 \\
18 \\
50,0\end{array}$ & $\begin{array}{l}36 \\
57,1 \\
35 \\
97,2\end{array}$ \\
\hline
\end{tabular}

EIA

\begin{tabular}{|c|c|c|c|c|c|c|c|c|c|c|c|c|c|}
\hline $\begin{array}{l}\text { TN } \\
\text { Beteiligung } \\
\text { Bestanden }\end{array}$ & $\begin{array}{l}n \\
\% \\
n \\
\%\end{array}$ & $\cdot$ & $\begin{array}{c}5 \\
9,6 \\
5 \\
100\end{array}$ & $\begin{array}{c}5 \\
9,6 \\
4 \\
80,0\end{array}$ & $\begin{array}{c}1 \\
2,8 \\
1 \\
100\end{array}$ & $\begin{array}{c}2 \\
5,6 \\
2 \\
100\end{array}$ & $\begin{array}{c}10 \\
19,6 \\
9 \\
90,0\end{array}$ & $\begin{array}{l}10 \\
19,6 \\
5 \\
50,0\end{array}$ & $\begin{array}{c}12 \\
24,0 \\
7 \\
58,3\end{array}$ & $\begin{array}{l}12 \\
24,0 \\
7 \\
\cdot 58,3\end{array}$ & $\begin{array}{l}24 \\
33,3 \\
16 \\
66,7\end{array}$ & $\begin{array}{l}24 \\
35,3 \\
16 \\
66,7\end{array}$ & $\begin{array}{lc}33 & 33 \\
51,6 & 52,4 \\
29 & 33 \\
87,9 & 100\end{array}$ \\
\hline
\end{tabular}

KBR

\begin{tabular}{|c|c|c|c|c|c|c|c|c|c|c|c|c|c|c|c|}
\hline $\begin{array}{l}\text { TN } \\
\text { Beteiligung } \\
\text { Bestanden }\end{array}$ & $\begin{array}{l}n \\
\% \\
n \\
\%\end{array}$ & $\begin{array}{c}6 \\
12,2 \\
6 \\
100\end{array}$ & $\begin{array}{c}6 \\
11,8 \\
6 \\
100\end{array}$ & $\begin{array}{c}7 \\
13,5 \\
6 \\
85,7\end{array}$ & $\begin{array}{c}7 \\
13,5 \\
6 \\
85,7\end{array}$ & $\begin{array}{c}5 \\
13,9 \\
5 \\
100\end{array}$ & $\begin{array}{c}5 \\
13,9 \\
2 \\
40,0\end{array}$ & $\begin{array}{c}3 \\
5,9 \\
3 \\
100\end{array}$ & $\begin{array}{c}3 \\
5,9 \\
2 \\
66,6\end{array}$ & $\begin{array}{c}4 \\
8,0 \\
4 \\
100\end{array}$ & $\begin{array}{c}4 \\
8,0 \\
1 \\
25,0\end{array}$ & $\begin{array}{c}7 \\
9.7 \\
6 \\
85.7\end{array}$ & $\begin{array}{c}7 \\
10,3 \\
6 \\
85,7\end{array}$ & $\begin{array}{c}8 \\
12,5 \\
3 \\
37.5\end{array}$ & $\begin{array}{c}8 \\
12,7 \\
6 \\
75,0\end{array}$ \\
\hline
\end{tabular}

IGM-AK

\begin{tabular}{|c|c|c|c|c|c|c|c|c|c|c|c|c|c|c|c|}
\hline $\begin{array}{l}\text { TN } \\
\text { Beteiligung } \\
\text { Bestanden }\end{array}$ & $\begin{array}{l}n \\
\% \\
n \\
\%\end{array}$ & $\begin{array}{c}8 \\
16,3 \\
8 \\
100\end{array}$ & $\begin{array}{c}8 \\
15,7 \\
8 \\
100\end{array}$ & $\begin{array}{c}13 \\
25,0 \\
13 \\
100\end{array}$ & $\begin{array}{c}13 \\
25,0 \\
5 \\
38,4\end{array}$ & $\begin{array}{c}9 \\
25,0 \\
8 \\
88,9\end{array}$ & $\begin{array}{c}9 \\
25,0 \\
7 \\
77,8\end{array}$ & $\begin{array}{c}22 \\
43,1 \\
22 \\
1,00\end{array}$ & $\begin{array}{l}22 \\
43,1 \\
9 \\
40,9\end{array}$ & $\begin{array}{l}16 \\
32,0 \\
15 \\
93,8\end{array}$ & $\begin{array}{c}16 \\
32,0 \\
16 \\
100\end{array}$ & $\begin{array}{l}35 \\
48,6 \\
28 \\
80,0\end{array}$ & $\begin{array}{l}36 \\
52,9 \\
32 \\
88,9\end{array}$ & $\begin{array}{l}43 \\
67,2 \\
37 \\
86,1\end{array}$ & $\begin{array}{l}41 \\
65,1 \\
38 \\
92,7\end{array}$ \\
\hline
\end{tabular}

n.a. $=$ nicht angefordert . 
Die INSTAND-Rötelnringversuche seit 1981 haben für die Ergebnisse des HHT bei positiven Seren mit 88,5 bis 97,3\% innerhalb der jeweils festgelegten Titerbereiche und bei negativen Seren mit 95,2 bis $100 \%$ richtiger Angaben noch akzeptable bis gute Gesamtergebnisse gezeigt.

Eine Übersicht über die mitgeteilten Ergebnisse im HIG weist eine deutlich größere Schwankungsbreite nach (Abb. 2). Hier zeigt sich der Unterschied zwischen einer weitgehend standardisierten Methode und einer Methode, für die solche Bemühungen noch ausstehen.

Für den ElA ergibt sich ein nur wenig besseres Bild (Abb.3). Die Erfolgsquoten schwanken zu stark, obwohl hier eine weitgehende Standardisierung durch die fast durchweg verwendeten industriell vorgefertigten Reagenzienzusammenstellungen angenommen werden kann.

In verschiedenen Studien und anderen Ringversuchen hat sich gezeigt, daß der HHT und der EIA als gleichwertig zu betrachten sind. Aus den Ergebnissen der Ringversuche ist dies nicht ersichtlich. Bei den starken Schwankungen der Teilnehmerergebnisse ist zu berücksichtigen, daß sich Seren mit geringem Antikörpergehalt finden, die gelegentlich im Enzym-Immuno-Assay positive Ergebnisse bei negativem HHT zeigen $(5,56,60)$. Solche Seren sind von Kleemann (26) auf die Spezifität der Reaktionen im Enzym-Immuno-Assay durch Blockierung mittels Rötelnantigen bestätigt worden. Wird jedoch bei solchen Vergleichen ein optimierter Hämagglutinationshemmtest

\begin{tabular}{|c|c|c|c|c|c|c|}
\hline \multicolumn{2}{|c|}{$\begin{array}{l}\text { Mai } 84 \\
\text { Probe }\end{array}$} & \multicolumn{2}{|c|}{$\begin{array}{l}\text { Nov. } 84 \\
\text { Probe }\end{array}$} & \multicolumn{3}{|c|}{$\begin{array}{l}\text { Mai } 85 \\
\text { Probe }\end{array}$} \\
\hline 21 & 22 & 41 & 42 & 21 & 22 & 23 \\
\hline $\begin{array}{r}77 \\
100 \\
77 \\
100\end{array}$ & $\begin{array}{c}73 \\
100 \\
71 \\
97,3\end{array}$ & $\begin{array}{c}65 \\
100 \\
63 \\
96,9\end{array}$ & $\begin{array}{c}66 \\
100 \\
63 \\
95,5\end{array}$ & $\begin{array}{c}81 \\
100 \\
78 \\
96,3\end{array}$ & $\begin{array}{c}78 \\
100 \\
69 \\
88,5\end{array}$ & $\begin{array}{c}81 \\
100 \\
74 \\
91,4\end{array}$ \\
\hline
\end{tabular}

\begin{tabular}{lllllll}
\hline 35 & 35 & 29 & 29 & 40 & 40 & 41 \\
45,5 & 48,0 & 44,6 & 43,9 & 49,4 & 51,3 & 50,6 \\
26 & 12 & 20 & 12 & 40 & 39 & 39 \\
74,2 & 34,2 & 68,9 & 41,3 & 100 & 97,6 & 97,5 \\
\hline \multicolumn{7}{c}{$--\cdot$} \\
\hline 43 & 43 & 40 & 40 & 48 & 49 & 49 \\
55,8 & 58,9 & 61,5 & 60,6 & 59,3 & 62,8 & 60,5 \\
43 & 43 & 27 & 29 & 47 & 42 & 42 \\
100 & 100 & 67,5 & 72,5 & 97,9 & 85,7 & 85,7 \\
\hline
\end{tabular}

\begin{tabular}{ccccccc}
\hline 8 & 8 & 5 & 5 & 5 & 6 & 6 \\
10,4 & 11,0 & 7,7 & 7,6 & 6,2 & 7,7 & 7,4 \\
8 & 8 & 5 & 3 & 4 & 5 & 5 \\
100 & 100 & 100 & 60,0 & 80,0 & 83,3 & 83,3 \\
\hline
\end{tabular}

\begin{tabular}{lllllll}
\hline 43 & 43 & 40 & 40 & & \\
55,8 & 58,9 & 61,5 & 66,7 & n.a. & n.a. & n.a. \\
37 & 27 & 39 & 37 & & & \\
86,1 & 62,8 & 97,5 & 92,5 & & & \\
\hline
\end{tabular}

eingesetzt, dann steigt ein positiver Antikörpernachweis im Hämagglutinationshemmtest stark an $(2,40)$. Bei diesen Ergebnissen handelt es sich um den Nachweis niedriger Titer, die in bezug auf einen eventuellen Immunschutz und die sich ergebenden juristischen Konsequenzen nur unter Vorbehalt zu bewerten sind. Buttler (6) hat gezeigt, daß durch eine Rötelnimpfung einer Gruppe von Erwachsenen mit positiver Impfanamnese, aber mit negativem Rötelntiter im HHT, bei allen Patienten der IgG-Antikörper-Titer angestiegen, ein rötelnspezifischer IgM-Antikörper aber nicht nachweisbar gewesen ist. Seren in den Entscheidungsbereichen "Immun/Nicht-Immun" bzw. "frischer/früherer Infekt" helfen, wenn sie in Ringversuchen eingesetzt werden, die Qualität der eigenen Untersuchungsergebnisse zu sichern. Impfseren zeigen oft $A n$ tikörpertiter in diesen Entscheidungsbereichen des HHT, des Bestätigungstests und bei der Bestimmung rötelnspezifischer Antikörper der Klasse IgM. Sie eignen sich daher für den Einsatz als Ringversuchsseren.

Die verschiedenen Standardmethoden für den HHT zeigen ihre positive Wirkung in den Ringversuchsergebnissen und werden besonders deutlich im Vergleich des HHT zu HIG und EIA. Für die beiden letzten Methoden sind Standardisierungsbemühungen dringend erforderlich.

Die Komplementbindungsreaktion (KBR) wird von wenigen Teilnehmern durchgeführt, für sie bestehen Standardisierungsvorschriften, die Ergebnisse können aber wegen der geringen Teilnehmerzahl nicht zuverlässig bewertet werden.

Die Beteiligung an der Bestimmung rötelnspezifischer Antikörper der Klasse IgM ist von zirka 16\% (1980) auf über $60 \%$ (1984) angestiegen. Dies ist in erster Linie dem zunehmenden Einsatz des EIA zuzuschreiben (siehe Tab.2). Die Beurteilung „Bestanden” muß wegen des Einsatzes von Impfseren, den damit zum Teil grenzwertigen Nachweisen und der juristischen Konsequenz eines "positiven" Nachweises, mit großer Zurückhaltung bewertet werden. Ein geeignetes Modell zur Bewertung und die Möglichkeit, Seren in ausreichender Menge nach Wildvirusinfektionen zu versenden, fehlen zur Zeit noch.

Bei der Bedeutung von Rötelnantikörperbestimmungen für die Schwangerschaft nehmen viel zu wenig Laboratorien an Röteln-Ringversuchen teil und lassen daher eine Absicherung ihrer Ergebnisse durch einen externen Vergleich mit den Resultaten anderer Laboratorien vermissen. Auch kann eine sinnvolle statistische Auswertung für die verschiedenen Methoden nur bei einer ausreichend großen Teilnehmerzahl erfolgen. Es ist daher zu wünschen, daß zukünftig die Teilnehmerzahl und damit die Vergleichbarkeit der Methoden zum Nutzen von Patient und Arzt zunehmen wird, da die Rötelnantikörperbestimmung heute eine Routineuntersuchung in vielen Laboratorien darstellt und ihre Bedeutung für die Schwangerschaft evident ist.

\section{Schrifttum:}

1. ANTONIADIS, G. et al.: Standardisierte Technik zur Durchführung des Röteln-HA und HHT. Bundesgesundheitsblatt 17, 22, 329-335 (1974).

2. BALFOUR, H. H., GROTH, K. E., EDELMANN, C. K.: Rubella viraemia and antibody responses after rubella vaccination and reimmunization. Lancet II, 1078-1080 (1981).

(1981). Nr.30: Rötelnschutzimpfungen. Bundesgesundheitsblatt 26, 148-150 (1983).

4. BIDWELL, D. E., BARLETT, A., VOLLER, A.: Enzyine immunoassays of viral diseases. J. Infect. Dis. 136, 274-278 (1977).

5. BUIMOVICI-KLEIN, E., O'BIERNE, A. J., MILLIAN, S. J., COOPER, L. Z.: LOW level rubella immunity detected by ELISA and specific lymphocytic transformation. Arch. Virol. 66, 321-327 (1981). 
6. BUTLER A B SCHYDLOWER M SCOTT R $M$ at . The immunoglobulin response to reimmunization with rubella vaccine. J. Pediatr. $99,531-534$ (1981). 7. Centers for Diseases Control: A procedurel guide to the performance of the standardized rubella hemagglutination inhibition test: Canters for Disease, Atlanta, Ga (1970).

8. Centers for Disease Control: Indirect hemagalutination lest for detection of rubella antibody (Current liem 255 August, 1977): Bureau of Laboratories, Perinatal Virology Branch 7-240. Allanta. Goorgia.

9. Conters for Disease Control: Rubella prevention: Morbid Mortal Weekly Rep. 30. $37 \div 42$ (1981).

10. College of Amorican Peiholngists: Pubella entibody. DATA ReCAP, 307-308 (1970-1980).

11. DALL. V., JENSEN, N. H. HANSEN, U.: Diegnosis of pre- and postnatal rubelie by demonstration of specific IgM-class antibodies by a microplate immunofluorescende test. Med. Microbiol. Immunol. 168, 73-80 (1980).

12. DOERR. H. W.: Rasche Isoliorung der Sorum-IgM.Antikörpor tür den Röteln. Hàmagglutinationahemmtest. Arzil. Lab. 25, 178-179 (1979)

13. DOERR. H. W., FLEISCHER, G., WIESMANN, M.: Nochwois von (Sub)klassonspezifischen IgG. und IgM.Rötolnantikörpor mit dom Enzymimmunoossoy (EIA). Im. mun. Infekt. 12, 21-28 (1984).

14. ENDERS, G. KNOTEK, F.: Comparison of the porformance and reproducebility kits for the direction of rubella antibodies. J. of Virol Mothods 11. 1-14 (1985).

15. ENDERS, G.. KNOTEK, F., PACHER, U.: Comparison of various serological methods and diagnostic kits for the detection of acute, rocent, and previous rubella infection, vaccination, an congenital infections. J. of med. Virol. 16, 219-232 (1985).

16. FRISCH. C., WHITESIDE. T. L.: A Comperison of the FIAX and hemagglutination inhibition test for lgG antibodies to rubella virus. J. Clin. Lab. Auto. 1, 33-37 (1981).

17. GOETZ, O.. PELLER, P.: Untersuchungen über die Zuverlässigkeit eines RötelnHAH-Test mit standardisierten Reagenzien. Ántl. Lab. 25, 305-308 (1979).

18. GRAVELL. M., DORSETT, P. H., GUTENSON, O., LEY, A. C.: Detection of antibody to rubella virus by enzyme-linked immunosorbent assay. J. Infect. Dis. 136. 300-303 (1977).

19. GREGG, N. N.: Congenital Cotaract following German measles in the mother. Trans. Ophthal. Soc. Aust. 3, 35-38 (1941).

20. GRILLNER, L., STRANNEGARD, O.: Evaluation of the hemolysis-in-gel-test for the screening of rubella immunity and the demonstration of recent infection. J. Clin. Microbiol. 3, 86-90 (1976)

21. HARRIS, R. E., JORDON, P. A., MONIF, G. R. G.: Rubella antibody titer: the significance of lowtitered rubella antibodies. Obstst. Gynecol. 52, 243-245 (1978). 22. INOUYE, S.: Micro-modification of kaolin treatment of Serum for the rubella hemagglutination-inhibition-test. J. Med. Microbiol. 9. 501-502 (1976).

23. IWASA, S., HORI, M.: Improved rubella hemagglutination inhibition test: inactivation of non-immunoglobulin hemagglutination inhibitors by phospholipase C. J. Clin. Microbiol. 4, 461-466 (1976)

24. JANKOWSKI, M. A., GUT, W., SWITALSKI, L. et al.: IgM fluorescence antibodies in sera of pregnant women exposed to rubella. Arch. Virol. 60, 123-130 (1979).

25. KALIMO K. O. K. MEURMAN, O. H., HALONEN, P. E. et al.: Solid-phase radioimmunoassay of rubella virus immunoglobulin $G$ and immunoglobulin $M$ antibodies. J. Clin. Microbiol. 4, 117-123 (1976).

26. KLEEMANN, K. T., KIEFER, D. J., HALBERT, S. P.: Rubella antibodies detected by several commercial immunoassay in hemagglutination inhibition-negative sera. $J$. Clin. Microbiol. 18, 1131-1137 (1983).

27. KRECH, U., WILHEM, J. A.: A Solid-phase Immunosorbent Technique for the Rapid Detection of Rubella IgM by Haemagglutination Inhibition. J. gen. Virol, 44, 281-286 (1979).

28. KURTZ, J. B., MORTIMER, P. P. et al.: Rubella antibody measured by radial hemolysis. Characteristics and performance of a simple screeening method for use in diagnostic laboratories. J. Hyg. 84, 213-222 (1980).

29. LEINIKKI, P. O., SHEKACHI, P., DORSETT, P., SEVER, J. L.: Enzyme-linked immunosorbent assay determination of specific rubella antibody level in micrograms of immunoglobulin $\mathbf{G}$ per milliliter of serum in clinical samples. J. Clin. Microbiol. 8, 419-423 (1978).
30. LENNETTE, E. H., SCHMIDT, N. J., MAGOFFIN, A. L.: Serology of rubella. Comparison of fluorescent antibody. complement lixation and neutralization test for diagnosis of current infections ond determination of sero-immunity. Calif. Med. 107 223-231 (1967).

31. LINDENSCHMIDT, E. G., LENNARTZ, H., LAUFS, R.: Vergleichende Studie über den Nachweis von rötelnspezifischen lgM.Antikörpern mit unterschiedlichen Methoden. Lab.med. 6. 54-58 (1982).

32. MANN, J. M. PREBLUD. S. R. HOFFMANN, R. E et al: Assessing risks of rubella infection during pregnency. JAMA 246, 1647- 1652 (1981).

33. MANN, J. J.. ROSSEN, R. D. et al.: The effect of kaolin in immunoglobulins. J. of Immunology 88, $1136-1141$ (1967).

34. MEEGAN, J. M., EVANS, B. K., HORSTMANN, D. M.: Comparison of the latex egglutination test with the hemagglutination inhibition test, enzyme-linked immunosorbent aseay and neutralization test for detection of antibodies to rubella virus. J. Clin. Microbiol. 16, 644-649 (1982)

36. MEATEN, U. P. in: Borovicżny, K. G. von, Merten, R., Merten, U. P.: Qualitätssicherung in dor Laboratoriumsmedizin: Qualitätssicherung in der Virusimmunologie (im Druck) (1986)

36. MERTENS, Th.: Der Röteln-Hämagglutinationshemmtest (HHT). Untersuchung zur Natur des sogenannten Seruminhibitors und zur Optimierung des Tests: Inaugural Dissertation zur Erlangung der Doktorwürde der Hohen Medizinischen Fakultat der Universität zu Köln (1976).

37. MERTENS, Th., ZIPPEL, C., SEUfFER, R., EGGERS, H. J.: Comparison of four different methods for detection of rubella lgM antibodies. Med. Microbiol. Immunol. 172, 181-189 (1983).

38. MEURMAN, O. H.: Antibody responses in patients with rubella infection determined by passive hemagglutination, hemagglutination inhibition, complement fixation and solid-phase radioimmunoassay test. Infect. Immun. 19, 369-372 (1978).

39. MIDDELTON, P. J., LARKE, R. P. B., LESSARD, P., DORAN, T. A.: Guide to the management of rubella problems. Can. Med. Assoc. J. 116, 484-488 (1977).

40. MORGAN-CAPNER, P. H., PULLEN, J. M., PATTISON, J. R. et al.: A comparison of three tests for rubella antibody screening. J. Clin. Pathol. 32, 542-545 (1979).

41. National Committee for Clinical Laboratory Standards: Standard for rubella hemagglutination-inhibition (HAI) reagent specifications and for a rubella $\mathrm{HAl}$ reference method: NCCLS, 771 E. Lancaster Avenue, Villanova, PA 19085 (1975).

42. REMINGTON, J. S., KLEIN, J. O.: Infectious Disease of the Fetus and Newborn Infant. Philadelphia, WB Saunders 82 (1976).

43. SANDER, J., NIEHAUS, Ch.: IgM-Enzym-Immuno-Screeningtest auf konnatale Röteln. DMW 109, 42, 1600-1603 (1984).

44. SEVER, J. L.: Congenital rubella. Clin. Perinatol. 6, 347-352 (1979).

45. SCHILT, U.: Rubella immunofluorescence as an alternative to hemagglutinationinhibition. Abstract, Swiss Soc. Microbiol. Experientia 34, 1664 (1979).

46. SCHNEWEIS, K. E., WOLFF, M. H., MARKL, G.: Sindbis-Virus zur Kontrolle de vollständigen Beseitigung spezifischer Inhibitoren bei Röteln HHT. Z Immun-Forsch. 144, 75-87 (1972).

47. SCHNEWEIS, K. E., WOLFF, M. H.: Die Röteln-passive Hämagglutination in Verbindung mit dem Hämagglutinationshemmtest. Ärztl. Lab. 25, 247-251 (1979).

48. SKENDZEL, L. P.: Current status of rubella testing. Am. J. Clin. Pathol. 76, 547580 (1981).

49. SKENDZEL, L. P.: Diagnosis of rubella immunity by laboratory tests. Medilab. 2-3. 37-41 (1985).

50. STEWART, G. L., PARKMAN, P. D. et al.: Rubella virus hemagglutination inhibition test. N. Engl. J. Med. 267, 554-557 (1967).

51. STRANNEGARD, O., GRILLNERT, L., LINDEBERG, I. M.: Hemolysis-in-gel-test for the demonstration of antibodies to rubella virus. J. clin. Microbiol. 1, 491-494 (1975).

52. SUGISHITA, C., O'SHEA, S., BEST, J. M., BANATVALA, J. E.: Rubella serology by solid-phase radioimmunoassay: its potential for screening programmes. Clin. Exp. Immunol. 31, 50-54 (1978).

53. TAYLOR, R. N., FULFORD, K. M., PRZYBYSZEWSKI, V. A., POPE, V.: Centre for Disease Control diagnostic immunology proficiency testing program results for 1977 Clin. Microbiol. 8, 388-395 (1978).
FormularService aus dem Verlag Kirchheim

Zu bestellen bei:

Verlag Kirchheim + Co GmbH Kaiserstraße 41, 6500 Mainz
Anmeldung/Rezeptwiederholung

Medikamentenverordnung

Krankenschein-Anmahnung

Erklärung Krankenschein-Nachlieferung

Erklärung Privatbehandlung

Notizen-Besprechung

Bescheinigung über Sprechstundenbesuch

Ärztliches Attest

Ärztliches Attest durchschreibend

Ärztliches Zeugnis

Ärztliche Bescheinigung

Ärztliche Diät-Bescheinigung

Ärztliche Bescheinigung für Schüler

Kurzer Arztbericht

(1 Block = 100 Blatt, Preise zzgl. Versandkosten + MwSt.
Best.-Nr. Preis DM

101

4,25

102

10.3

104

105

106

107

108

$108 \mathrm{~A}$

109

110

111

112

113

4,25

5,13 
54. TAYLOR, R. N., FULFORD, K. M.: Assessment of laboratory improvement by the Center for Disease Control diagnostic immunology proficiency testing program. J. Clin. Microbiol. 13, 356-368 (1981).

55. VAN DER LOGT, J. T. M. VAN LOON, A. M. VAN DER VEEN, J. Hemabsorption immunosorbent technique for determination $M$ antibody. J. Clin. Microbiol. 13, 410415 (1981).

56. VEJTORP, M.: Enzyme-linked immunosorbent assay for determination of rubella IgG antibodies. Acta Pathol. Microbiol. Scand. Sect. (B) 86, 382-392 (1978).

57. VEJTORP, M., FANOE, E., LEERHOY, J.: Diagnosis of postnatal rubella by the enzyme-linked immunosorbent assay for rubella lgM and lgG antibodies. Acta Pathol. Microbiol. Scand. Sect. (B) 87, 155-160 (1979).

58. VEJTORP, $M$. MANSA. B.: Rubella IgM antibodies in sera from infants born after maternal rubelle later than the 12 th week of pregnancy. Scand. J. Infect. Dis. 12 , $1-5$ (1980).

59. VEJTORP, M., LEERHOY, J.: Brief report. Comparison of the sensitivity of ELISA and the hemagglutination-inhibition test for routine diagnosis for rubella. Acta Pathol. Microbiol. Scand. Sect. (B) 88, 349-350 (1980).

60. WEISSFELD, A.S., GEHLE, W. D., SONNENWIRTH, A. C.: Comparison of several test systems used for determination of rubella immune status. J. Clin. Microbiol. 16. 82-85 (1982).

61. WOLFF, M. H., SENGFELDER, H., BUCK, Th., SCHNEWEIS, K. E.: Nachweis von röteln-spezifischen lgM-Antikörpern nach Trennung der Immunglobuline durch lonenaustauschchromatographie. Ärztl. Lab. 29, 40-44 (1983).

62. ZIPPEL, C., FEDERMANN, G., LEIDEL, J., EGGERS, H. J.: Nachweis von Rötelnvirusantikörpern mit dem Hämolysis-in-Gol-Test. Ärztl. Lab. 27, 48-51 (1981).

Anschrift des Verfassers:

Dr. med. Utz P. Merten

Dürener Straße 199

5000 Köln 41

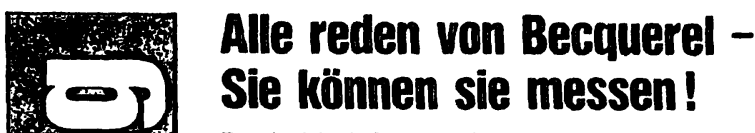

Berthold-Meßgerăte für Radioaktivität und Kernstrahlung werden seit 40 Jahren in Industrie, Wissenschaft und Medizin erfolgreich eingesetzt. Zur Messung der Radioaktivität in Milch, Fleisch und anderen Lebensmitteln bietet Berthold an:

Tragbare Monitoren zur orientierenden Vor-Ort-Messung mit Nachweisgrenzen (je nach Radionuklid) bis herab zu einigen $100 \mathrm{~Bq} / \mathrm{l} \mathrm{bzw}$. Bq/kg.

Gamma-Meßplätze zur Labormessung mit Nachweisgrenzen bis herab zu einigen $\mathrm{Bq} / \mathrm{l} \mathrm{bzw}$. Bq/kg (0,4 I Meßvolumen) oder unter $1 \mathrm{~Bq} / \mathrm{l} \mathrm{bzw} .1 \mathrm{~Bq} / \mathrm{kg}(1,5$ I Meßvolumen)

Low-level-AlphaBeta-MeBplätze für Auswertung radiochemischer Nuklidanalysen mit Nachweisgrenzen weit unter $0,1 \mathrm{~Bq}$.
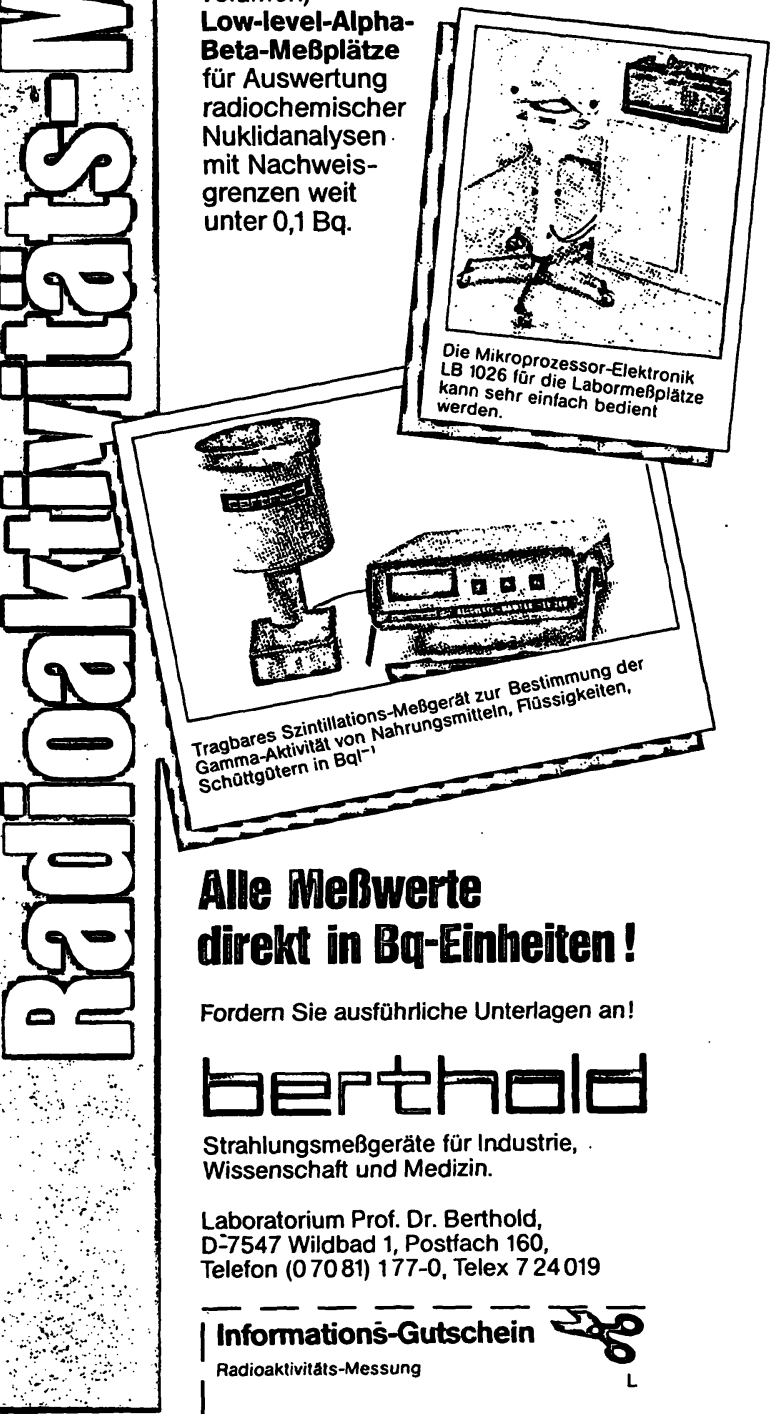

Eerre
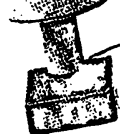

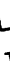

Hations-MeBgerat zur Beslimsigkeilen. ragbares Szinitit uon Nahru na-Aktivilat $\mathrm{Bal}^{-1}$ Schütgó

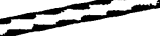

\section{Alle MheBwerte} direkt in Bq-Einheiten!

Fordern Sie ausführliche Unterlagen an!

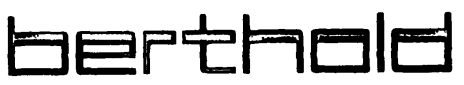

Strahlungsmeßgeräte für Industrie, Wissenschaft und Medizin.

Laboratorium Prof. Dr. Berthold D=7547 Wildbad 1, Postfach 160 , Telefon (07081) 177-0, Telex 724019

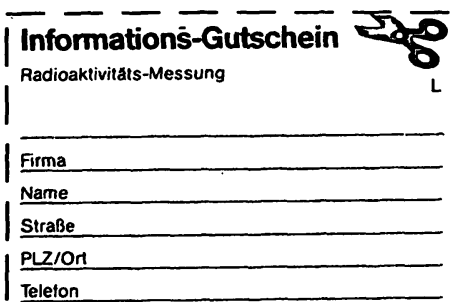

